\title{
Parent involvement in novice teen driving: a review of the literature
}

\author{
B Simons-Morton, M C Ouimet
}

See end of article for

Injury Prevention 2006;12(Suppl I):i30-i37. doi: 10.1136/ip.2006.011569

authors' affiliations

Correspondence to: Dr B Simons-Morton, Prevention Research Branch, Division of Epidemiology, Statistics, and Prevention Research National Institute of Child Health and Human Development, 6100 Executive Boulevard, 7B05, Bethesda, MD 20892-7510, USA mortonb@mail.nih.gov

\begin{abstract}
Motor vehicle crashes remain elevated among novice teen drivers for at least several years after licensure. Licensing policies and driver education are the two primary countermeasures employed to decrease young driver crash risks. Graduated driver licensing policies have proved to be effective in reducing crash rates where evaluated. Driver education is an essential part of teaching teens the rules of the road and operating a vehicle, but requires few hours of professional driver training, relying mainly on parents to provide most of the supervised practice driving teens obtain before independent driving licensure. The few studies that have been conducted to increase parent supervised practice driving have not shown positive results. Moreover, it is unclear that increases in practice would improve independent driving safety. Recent research has shown that parent management of the early independent driving experience of novice teens improves safety outcomes, and other research has shown that it is possible to increase parent management practices. This paper provides a review of the literature on parent involvement in supervised practice and independent driving, and efforts to increase parental management.
\end{abstract}

M otor vehicle crashes are highly elevated among novice teen drivers for years after licensure in most countries and are the leading cause of injury and death among teens aged 16-19 years in the US. ${ }^{12}$ Young driver crash risks remain elevated into the twenties, but driving is particularly dangerous during the early months and years of licensure. The major countermeasures for decreasing young driver risk include driver education, licensing policies, and parent management. Driver education is an essential part of teaching teens the rules of the road and operating a vehicle, but requires few hours of professional driver training, relying mainly on parents to provide most of the practice driving teens need to develop their driving skills. However, surprisingly little is known about the amount and nature of the parent supervised driving experience. While a certain amount of practice is essential, the available evidence suggests that even a substantial amount may not protect against independent driving crash outcomes. ${ }^{3-5}$

\section{GRADUATED DRIVER LICENSING}

Graduated driver licensing (GDL) is a policy innovation now accepted widely in the US, Canada, Australia, New Zealand, and some European countries. Typically GDL policies increase the period of the learner's permit (which tends to delay licensure). In the US, GDL also restricts driving among novices under certain conditions such as night driving, thereby limiting exposure to the most dangerous driving conditions while teens gain experience and develop driving competence. ${ }^{6}$ GDL programs have effectively reduced motor vehicle crashes where adopted ${ }^{7-10}$ and these policies enjoy wide public support. ${ }^{11-13}$ However, the provisions of GDL range considerably from one country to another and in the US from state to state. While driver education and GDL policies are institutionalized in most US states, policies are much stronger in some states than others. In general, GDL policies tacitly recognize the importance of parent involvement in teaching and managing novice teen drivers, and some policies explicitly require certain amounts of supervised practice driving. However, parent involvement is not systematically emphasized by these policies or novice driver programs associated with them.

Parent management of novice teen driving has rarely been studied systematically. ${ }^{14}$ There remain huge gaps in what is known about how parents teach their teenage children to drive, decide when they are ready to test for a license, and manage the early independent driving experience. However, there is a growing literature on the effectiveness of interventions to increase parental management of newly licensed teens during the initial independent driving period. In this paper, we review the literature on parent involvement in supervised practice and independent driving, including recent and ongoing research on efforts to increase and improve parent management.

\section{Driver education and supervised practice driving}

Driver education is available in every US state in one form or another, but it is not universally required, and most states provide alternatives for satisfying or opting out of driver education altogether. Nevertheless, most US teenagers take some form of driver education that usually includes about 30 hours of classroom training and six hours of behind the wheel instruction. In general studies have shown that driver education programs have no effect on post-licensure crash rates. ${ }^{15-17}$ Moreover, when policies increase the possibility of independent driving at a younger age after completing a driver education program, ${ }^{17-19}$ crash risk is elevated. ${ }^{18-21}$

The obvious reason that driver education programs do not provide novice teen driver safety benefits is because they typically include far too few hours of professional on road instruction for more than rudimentary development of basic maneuvering skills (such as lane keeping and speed maintenance). Possibly, given enough hours, professional driver training might provide safety effects, particularly if it included higher order skills (such as hazard detection, risk perceptions, and attitudes about driving) as part of the curriculum (see Berg in this issue, ${ }^{22}$ and Gregersen ${ }^{23}$ ).

Abbreviations: DMV, Department of Motor Vehicles; GDL, graduated driver licensing; NETS, Network of Employers for Traffic Safety. 
However, substantial increases in mandated professional training seem unlikely.

While some studies have been conducted on the best ways to teach different aspects of driving, research on how to instill in novice teen drivers the skills, perceptions, and attitudes required of safe driving is not well advanced. Similarly, other than to assure safety while teens learn to drive during the supervised practice driving stage, it is not completely clear what parents should do or even how much and what types of practice they should provide. Nevertheless, because the amount of on-road professional driver training is practically limited to the few hours mandated by state licensing policy, parents are likely to remain the primary agents responsible for preparing teenagers for independent driving.

\section{PARENT INVOLVEMENT IN SUPERVISED PRACTICE DRIVING}

In the US parents have traditionally taught their teenage children to drive and driver education and licensing requirements have been designed with this in mind. While GDL policies are primarily intended to limit exposure to the highest risk conditions during the novice driving period, in many states the policies adopted have also increased the learner's permit period, delaying licensure somewhat and providing increased opportunity for parents to participate in their children's driving education. ${ }^{24}$ Some GDL policies require as much as 50 hours of parent supervised practice driving during the learner's permit period before testing for a license. ${ }^{25}$ Recent estimates of the amount of parent supervised practice driving US teens actually receive before licensure have ranged from about 40-50 hours in North Carolina where there is no specific requirement, ${ }^{26}$ to 75 hours in Michigan which requires a minimum of 50 hours. ${ }^{12}$

\section{Effects of parent supervised practice driving}

It is unknown how much supervised practice novice teen drivers actually need to gain higher order skills. Moreover, there is limited research on the effects of extensive practice on independent driving performance. Nevertheless, in general it can probably be assumed that novices can learn to manage a vehicle moderately well in only a few hours of practice, ${ }^{27}$ and substantial supervised practice would be expected to better prepare novice teenagers for independent driving to the extent that it provided them with a wide range of driving experiences that would foster the development of higher order skills.

Evidence from studies conducted in the US and Europe evaluating the effect of supervised practice driving on teen driving outcomes is inconclusive. In one American study, in which the average amount of supervised practice was about 570 kilometers, no relationship was found between the amount of practice and the rate of post-licensure crashes. ${ }^{3}$ Similarly, results of a Norwegian study in which learners drove for about 1150 kilometers under supervision (and 600 in drivers' training) also found no effect of practice on postlicensure crash. ${ }^{5}$ Also, another study conducted in France reported no safety effects from substantial supervised practice driving. This study showed that learners who drove an average of about 5000 kilometers with parent supervision after 20-25 hours of professional on-road training had postlicensing crash rate similar to learners who had only the professional on-road training. ${ }^{48}$ Studies conducted in Sweden have reported a positive effect of practice driving. Researchers showed that an average of about 120 hours of supervised driving ${ }^{29}$ later reported as being 5880 kilometers, ${ }^{31}$ and about 3800 kilometers of supervision (and 450 in drivers' training $)^{5}$ beginning as early as 16 years of age and extending over a period of about two years had a positive impact on post-licensure crash rate compared to learners who had no supervision. $^{529}$ The implications of the European studies for the US population cannot be determined because they were not true randomized trials, the supervised practice driving period was quite long, study participants with extra practice got their licenses almost one year earlier than the comparison group in the French study and one month earlier in the Swedish study, and licensure did not occur until age 18. Further research is needed to determine if extensive supervised practice driving protects against independent driving safety risks and how much and what type of practice may be important.

\section{Process of parent supervised practice driving}

As little is known about the effect of supervised driving practice on independent driving safety, less is known about how parents go about training their teenage children to drive, how much instruction they provide, and the range, timing, and nature of their driving experiences. Only a few studies have investigated the parent supervised practice driving period. In Goodwin et al, ${ }^{26}$ US parents and teens reported a reasonably positive experience, with parents providing some specific instruction and not often getting upset. However, teens' and parents' perceptions about the experience varied somewhat. The survey did not cover the entire one year minimum learner's permit period, so not much could be learned about how practice varied over the permit period. A study conducted in France $^{48}$ found that teens reported nearly three times more relationship difficulties with parents over supervised practice driving compared with their relationships in daily life, suggesting that it may place substantial stress on the parent-teen relationship. The study also indicated that despite substantial amounts of practice over a period of 1-3 years before licensure, the type of experience was limited because many of the driving hours were completed on long drives while on vacation or as part of routine trips to school, with relatively few kilometers dedicated to the practice of a specific skill or situation. While only preliminary, other results obtained with a small subsample indicated that this long term supervised driving was associated with detrimental effects, possibly due to parents serving as vigilant passengers, termed "team driving". Some young drivers reported having trouble managing blind spots once they were driving independently, possibly because parents had largely assumed this responsibility during supervised driving. As suggested by Groeger, ${ }^{30}$ novice teens may not fully develop scanning and other important safe driving habits during the supervised driving period because they rely on verbal feedback provided by supervising parents.

\section{Parent supervised practice driving: issues}

While supervised practice driving tends to be very safe, ${ }^{31}{ }^{32}$ it appears that a lot of learning occurs during the initial six months or so of independent driving, ${ }^{3}{ }^{32}$ apparently regardless of the amount of supervised practice driving and largely without continuing instruction after licensure. ${ }^{3}$ There are several possible reasons why the amount of parent supervised practice may not be the most important factor in novice driver training and outcomes. Parents could be limiting practice driving to relatively safe conditions, restricting the manifestation of risky behaviors, and providing substantial passenger vigilance and feedback. These efforts may contribute mainly to basic maneuvering skills and less to higher order skills and post-licensure crash prevention.

Parents are responsible for most supervised practice driving, but little is known about how much and what kind of practice driving they should and do provide. Little is known about the extent to which the type and intensity of supervised practice driving varies over time or from one teen 
to the next. Do teens get most of their practice right after getting a learner's permit and just before testing for an independent driving license? Are teens gradually exposed to more complex driving situations? Also, more needs to be learned about how the parent-teen relationship affects and is affected by this experience, extending the preliminary work started by Goodwin et $a l^{26}$ and Page et al. ${ }^{48}$ Little is known about how parents determine when their teen is ready to obtain a license for independent driving. Also, we do not know how the practice driving experience may influence parent management of novice teen driving. Do parents assume because their child has learned to manage the vehicle and traffic reasonably well, refrained from risky driving behavior during supervised practice driving, and managed to get an independent driving license that the teenager is a proficient and safe driver?

\section{PARENT INVOLVEMENT IN THE MANAGEMENT OF INDEPENDENT DRIVING OF NOVICE TEENAGERS}

The key to preventing motor vehicle crashes at every level is reducing exposure. The more kilometers driven, the greater the risk of a crash. Therefore, delaying licensure and minimizing the amounts novice teenagers drive after licensure would reduce crash risk, which is highest in the first month of licensure, declines rapidly for about six months, ${ }^{32}$ then continues to decline at a much more modest rate for another two years. ${ }^{32}$ This suggests that the independent driving experience is an important aspect of driver safety and introduces the following dilemma: driving competence develops mainly through independent driving experience, but the more novice teenagers drive the greater the likelihood of a crash. A partial solution to this dilemma is to encourage novice teens to drive, but only under less dangerous driving conditions. Crash risks are particularly high for teen drivers under certain conditions, and substantial improvements in teen driver safety can be obtained by restricting the conditions under which they drive. GDL policies in the US restrict novice teen independent driving for a period of time under the most dangerous driving conditions by restricting driving late at night, and in some cases limiting the number of passengers. But these limits are minimal and other high risk driving conditions are not generally limited by GDL, leaving parents to manage risk with little guidance from policy or elsewhere.

A number of observational studies have examined aspects of parent management and its effects on novice teen independent driving. In general, the research indicates that most parents place at least modest restrictions on driving by newly licensed teens, but that these limits tend not to be very strict and not to last very long. Nevertheless, the research is quite clear that risky driving, traffic violations, and crashes are lower among teens whose parents apply restrictions. A review of key studies, outlined in table 1, follows.

One of the first studies to examine the relationship between parent involvement and driving outcomes was a retrospective survey of licensed high school teens who were asked about their current driving practices and about the driving limits imposed by their parents when they first became licensed. ${ }^{33}$ A number of associations with driving performance were found, as indicated in table 1. Specifically, parental control and restriction on teen passengers had a positive impact on frequency of violations and crashes. In another study, McCartt et al ${ }^{3}$ demonstrated the positive effect of parental restrictions on crashes after licensure. Two prospective studies conducted with novice teens showed that parental monitoring predicted teen risky driving behavior after licensure. In the first study, newly licensed high school students were interviewed twice, three months apart. ${ }^{34}$ Higher levels of risky driving behavior reported at follow up were predicted by initial reports of risky driving, attitudes more accepting of deviant behavior, less parental monitoring of driving, and fewer restrictions. The second study surveyed teens and parents at the time the teen obtained a permit and again one year later. ${ }^{35}$ Parents reported delaying teen licensure until they felt the teen was ready. Nearly all parents reported imposing driving limits on their newly licensed teens, particularly trip limits (those involving where the teen was going and when they would be back), but fewer and not very strict limits on driving conditions (those known to be associated with teen crash risk, such as night driving, teen passengers, and high speed roads). Young age at licensure, male gender, low risk perceptions, higher parent-teen conflict about driving, and low parental monitoring predicted risky driving in multivariate analyses. In another study, parents of teens testing for learner permits were interviewed about their intended limits. ${ }^{36}$ Predictably, parents intended to impose substantial limits on trip conditions, but not on risk conditions. A third of parents reported establishing some form of parent-teen agreement about driving limits without being asked to do so by the research team. However, we do not have information about the terms of these agreements. Intended limits were greater among parents who reported more parental monitoring of teen behavior, higher risk perceptions, more discussions with teens about driving rules, and less vehicle access.

To learn more about parent management practices, indepth interviews were conducted with 24 parents and newly licensed teens. ${ }^{37}$ Parents reported a large number of rules, few restrictions on risky conditions, and talking or warning as the primary consequences for most violations of the rules, with limiting driving privileges a less likely consequence. Discordant perceptions of parents and teens about driving privileges and consequences have frequently been reported. For example, Beck, Hartos, and Simons-Morton ${ }^{38}$ interviewed teens and parents at one month post-licensure. Discordance between parent and teen reports on both driving limits and likely consequences for violating driving rules were associated with greater risky driving. Typically, discordance occurs when parents believe they have communicated their expectations to their children about driving, but the latter believe they have been granted greater driving privileges than they have, leading to poor compliance with parent imposed rules. Discordance probably reflects poor parent-teen communication. One advantage of parent-teen driving agreements is their potential to clarify parent expectations and consequences for violations of the rules.

One possible effect of GDL might be to increase perceived social norms about the risk of teen driving and the importance of parent limits on novice teen drivers. ${ }^{24}$ Goodwin and Foss $^{39}$ interviewed parents and teens at the time of teen intermediate or full licensure about GDL. Most of those interviewed were aware of the GDL restrictions and most reported close adherence to them. A small number of parents allowed their teens to drive in violation of the rules and a larger minority of teens reported breaking the rules about teen passengers. This survey suggests that parents are important enforcers of GDL. Not surprisingly, most teens reported little concern about detection by law enforcement, but indicated driving carefully to avoid unnecessary risk of detection. The researchers also interviewed a sample of law enforcement officers, who reported support for GDL but scant understanding of the provisions, and therefore considered this a low enforcement priority. While active enforcement of GDL provisions would appear to be limited, this survey suggests that even the possibility of passive enforcement of the provisions may have important effects on driving behavior. Relatedly, GDL may enhance parent limits on novice teen driving. In the only study to have addressed this 
Table 1 Research on associations between parental restrictions and teen driving

\begin{tabular}{|c|c|c|}
\hline Study & Design; sample; purpose & Results \\
\hline $\begin{array}{l}\text { Hartos, Eitel, Haynie, } \\
\text { Simons-Morton }\end{array}$ & $\begin{array}{l}\text { Retrospective survey; } n=300 \text { licensed HS students; } \\
\text { assess associations with teen driving outcomes }\end{array}$ & $\begin{array}{l}\text { Associations with risky driving } \\
\text { - Parental monitoring (-) } \\
\text { - Self control (-) } \\
\text { - Deviance acceptance (+) } \\
\text { - Problem friends (+) } \\
\text { Associations with violations } \\
\text { - Time licensed (+) } \\
\text { - Restrict teen passengers (-) } \\
\text { - Parental control (-) } \\
\text { Associations with crashes } \\
\text { - Restrict teen passengers (-) }\end{array}$ \\
\hline $\begin{array}{l}\text { McCartt, Shabanova, } \\
\text { Leaf }^{3}\end{array}$ & $\begin{array}{l}\text { Prospective survey with } 6 \text { month follow ups from } \\
\text { freshmen to senior grades; } n=911 \mathrm{HS} \text { students; assess } \\
\text { effect of driving experience on teen driving outcomes }\end{array}$ & $\begin{array}{l}\text { Crash and conviction rates higher in first month of independent driving } \\
\text { Associations with violations } \\
\text { Male gender (+) } \\
\text { - GPA (-) } \\
\text { Rural area (+) } \\
\text { Associations with crashes } \\
\text { Parental restrictions (-) } \\
\text { - GPA (-) }\end{array}$ \\
\hline $\begin{array}{l}\text { Hartos, Eitel, Simons- } \\
\text { Morton }^{34}\end{array}$ & $\begin{array}{l}\text { Prospective survey with } 3 \text { month follow up; } n=261 \\
\text { licensed HS students; assess predictors of risky driving }\end{array}$ & $\begin{array}{l}\text { Predictors of risky driving } \\
\text { Baseline risky driving }(+) \\
\text { - Deviance acceptance (+) } \\
\text { - Parental monitoring (-) } \\
\text { Parental restrictions (-) }\end{array}$ \\
\hline $\begin{array}{l}\text { Hartos, Eitel, Simons- } \\
\text { Morton }^{35}\end{array}$ & $\begin{array}{l}\text { Prospective survey with } 1 \text { year follow up; } \mathrm{n}=275 \\
\text { parent-teen dyads recruited at permit, } 161 \text { of whom } \\
\text { were licensed and interviewed } 1 \text { year later; assess } \\
\text { parent management and predictors of risky driving }\end{array}$ & $\begin{array}{l}\text { Parent management } \\
\text { - Parents delayed license testing until teen was ready } \\
\text { - Parents placed more limits on trip than risk conditions } \\
\text { Predictors of teen risky driving } \\
\text { - Young age at license (+) } \\
\text { - Male gender (+) } \\
\text { - Risk perceptions (-) } \\
\text { - Parent-teen conflict over driving (+) } \\
\text { Parental monitoring (-) }\end{array}$ \\
\hline $\begin{array}{l}\text { Hartos, Beck, Simons- } \\
\text { Morton }^{36}\end{array}$ & $\begin{array}{l}\text { Cross sectional survey; } n=658 \text { parents of teens testing } \\
\text { for a permit; assess parents' intended limits }\end{array}$ & $\begin{array}{l}\text { Parents' intended limits } \\
>\text { trip conditions } \\
<\text { risk conditions } \\
\text { Associations with intended limits } \\
\text { Parental monitoring (+) } \\
\text { Risk perceptions (+) } \\
\text { - Discussions about driving rules (+) } \\
\text { - Vehicle access (-) }\end{array}$ \\
\hline $\begin{array}{l}\text { Hartos, Shattuck, } \\
\text { Simons-Morton, Beck }\end{array}$ & $\begin{array}{l}\text { In-depth interviews; } n=24 \text { parents and newly licensed } \\
\text { teens; assess parent driving rules }\end{array}$ & $\begin{array}{l}\text { Parent rules } \\
143 \text { different rules } \\
\text { - Rules not strict } \\
\text { - Tansequences for rules violations (more likely) } \\
\text { - Take away driving privileges (less likely) }\end{array}$ \\
\hline $\begin{array}{l}\text { Beck, Hartos, Simons- } \\
\text { Morton }^{38}\end{array}$ & $\begin{array}{l}\text { Cross sectional survey at } 1 \text { month post licensure; } \\
\mathrm{n}=579 \text { parents and newly licensed teens; examine } \\
\text { associations with risky driving }\end{array}$ & $\begin{array}{l}\text { Associations with risky driving } \\
\text { Discordance on restrictions (+) } \\
\text { - Discordance on consequences for violating rules (+) }\end{array}$ \\
\hline Goodwin, Foss ${ }^{39}$ & $\begin{array}{l}\text { Cross sectional survey; } \mathrm{n}=900 \text { parents and teens after } \\
\text { intermediate or full licensure; are parents and teens } \\
\text { aware and do they adhere to GDL? }\end{array}$ & $\begin{array}{l}\text { Parents and teens } \\
\text { - High awareness of rules } \\
\text { - } 10 \% \text { of teens violate night rules, } 15 \% \text { with parent permission } \\
\text { - Teens reported little concern about detection, but drove to avoid it }\end{array}$ \\
\hline $\begin{array}{l}\text { Hartos, Simons-Morton, } \\
\text { Beck, Leaf }{ }^{40}\end{array}$ & $\begin{array}{l}\text { Prospective surveys within } 4 \text { months of licensure; } \\
n=292 \text { parent-teen dyads in MD; } 108 \text { dyads in } C T \text {; } \\
\text { determine whether parent limits are stricter in } M D \\
\text { with GDL or CT without GDL }\end{array}$ & $\begin{array}{l}\text { Parent limits stricter with GDL } \\
\text { Teen passengers } \\
\text { High speed roads } \\
\text { - Night driving } \\
\text { - Overall limits }\end{array}$ \\
\hline
\end{tabular}

HS, High School; MD, Maryland; CT, Connecticut; GDL, graduated driver licensing; (+), positive effect or improvement; $(-)$, negative or detrimental result.

issue, parent limits on the driving conditions of novice teen drivers in a GDL state over the first year of licensure were compared with parent limits in a non-GDL state over a similar period. ${ }^{40}$ Limits were found to be more strict in Maryland, a GDL state, on teen passengers, night driving, and high speed roads than Connecticut, a state without GDL at the time.

Monitoring teens after licensure is promoted by a number of companies which market devices-mostly adapted fleet control devices-allowing parents to monitor elements of their teen's driving including speed, location, rapid acceleration or deceleration, and video recording of events such as crashes or near crashes. As the availability and diversity of these technologies increase, evaluation studies will be needed to determine their potential utility. While these devices could be useful adjuncts for parent supervision, many questions remain unanswered. How would parents actually use these devices? How would the parent-teen relationship be affected by the use of these devices? Would parents' use of these devices increase teen safety?

In summary, parents tend to deal with their concerns about teen independent driving by emphasizing trip conditions so that they know where the teen is and when they will return with the car, but set rather modest limits on risk conditions, and these limits decline rapidly over time. However, teens whose parents establish and maintain 
Table 2 Interventions to increase parental driving supervision and management of independent driving

\begin{tabular}{|c|c|c|}
\hline Study & Design; sample; purpose & Results \\
\hline $\begin{array}{l}\text { Supervised practice driving } \\
\text { Goodwin, Waller, Foss, } \\
\text { Margolis }^{26}\end{array}$ & $\begin{array}{l}\text { Randomized trial; } n=528 \text { parent-teen dyads recruited during } \\
\text { the learner's permit stage; evaluate effects on supervised } \\
\text { practice driving of NETS materials }\end{array}$ & - No significant treatment group differences \\
\hline $\begin{array}{l}\text { Chaudhary, Ferguson, } \\
\text { Herbel }^{41}\end{array}$ & $\begin{array}{l}\text { Randomized trial ( } 3 \text { groups); } n=500 \text { parents/group; evaluate } \\
\text { effects of NETS and other materials on supervised practice } \\
\text { driving and parent management of teen driving after licensure }\end{array}$ & $\begin{array}{l}\text { - High satisfaction with materials } \\
\text { - No significant treatment group differences }\end{array}$ \\
\hline \multicolumn{3}{|c|}{ 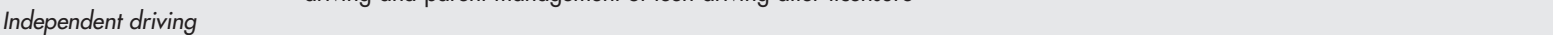 } \\
\hline $\begin{array}{l}\text { Hartos, Nissen, } \\
\text { Simons-Morton }\end{array}$ & $\begin{array}{l}\text { Prospective interviews at license with } 3 \text { month follow up; } \\
n=47 \text { parent-teen dyads recruited from private driving schools; } \\
\text { evaluate the acceptability of the Checkpoints Program }\end{array}$ & $\begin{array}{l}\text { - Families reported liking the agreement } \\
\text { - Most adopted limits } \\
\text { - Teen passengers } \\
\text { - High speed roads } \\
\text { - More limits at follow up than initial intent }\end{array}$ \\
\hline $\begin{array}{l}\text { Simons-Morton, Hartos, } \\
\text { Beck }^{44} 45\end{array}$ & $\begin{array}{l}\text { Randomized trial with assessment at license, 1, 4, and } 9 \text { months; } \\
\mathrm{n}=658 \text { parent-teen dyads; test the efficacy of the Checkpoints } \\
\text { Program (video, parent-teen driving agreement, personal } \\
\text { admonishment) delivered at time of teen licensure at DMV }\end{array}$ & $\begin{array}{l}\text { With Checkpoints } \\
\text { More strict driving limits } \\
\text { - Night driving } \rightarrow 1 \text { month } \\
\text { - Passengers and high speed roads } \rightarrow 4 \text { months } \\
\text { - Overall limits } \rightarrow 9 \text { months } \\
\text { Parents } 3 \text { times more likely to report adopting and } \\
\text { maintaining a parent-teen agreement }\end{array}$ \\
\hline $\begin{array}{l}\text { Simons-Morton, Hartos, } \\
\text { Leaf, Preusser }^{43}\end{array}$ & $\begin{array}{l}\text { Randomized trial with assessments at baseline, licensure, } 1,3,6 \text {, } \\
\text { and } 12 \text { months post-licensure; } n=469 \text { parent-teen dyads } \\
\text { recruited at time teen obtained a learner's permit; evaluate } \\
\text { the efficacy of the Checkpoints Program }\end{array}$ & $\begin{array}{l}\text { With Checkpoints } \\
\text { - More strict driving limits } \rightarrow 12 \text { months } \\
\text { - Predictors of driving limits } \\
\text { - Teen and parent expectations (+) } \\
\text { - Male gender (+) } \\
\text { - Limits at license (+) }\end{array}$ \\
\hline $\begin{array}{l}\text { Simons-Morton, Hartos, } \\
\text { Leaf, Preusser }^{46} 47\end{array}$ & $\begin{array}{l}\text { Randomized trial with assessments at baseline, licensure, } 1,3,6 \text {, } \\
\text { and } 12 \text { months post license; } n=3743 \text { parent-teen dyads recruited } \\
\text { at time of teen permit; test the effectiveness of the Checkpoints } \\
\text { Program on teen driving outcomes (recruitment at permit) }\end{array}$ & $\begin{array}{l}\text { With Checkpoints } \\
\text { Driving limits }(+) \\
\text { - Risk perceptions }(+) \\
\text { Outcome expectations }(+) \\
\text { - Expected limits (+) } \\
\text { Lower driving outcomes }{ }^{(a)} \text { at } 12 \text { months and indirect } \\
\text { effect through limits }{ }^{(b)} \\
\text { - Risky driving (a-b) } \\
\text { - Violations } s^{(a-b)} \\
\text { - Crashes }{ }^{(b)}\end{array}$ \\
\hline
\end{tabular}

NETS, Network of Employers for Traffic Safety; DMV, Department of Motor Vehicles.

relatively strict limits during early independent driving are less likely to engage in risky driving or to have traffic violations or crashes during the first year of licensure.

\section{INCREASING PARENTAL MANAGEMENT OF NOVICE TEEN DRIVERS}

Surprisingly little research has focused on increasing parent management of teen driving to reduce teen driving risk. ${ }^{14} \mathrm{~A}$ limited number of studies has been conducted evaluating interventions to increase parent involvement in supervised practice driving during the learners' permit period. A more extensive literature has been developed evaluating efforts to increase parental management of independent driving among novice teenagers.

\section{Increasing parenting involvement in supervised practice driving}

Here we address the question of the extent to which and how best to facilitate parent supervised practice driving. As noted, there are many difficulties associated with professional driver education, beyond the typically limited amount of on-road training possible. Other problems relate to what should be taught after a novice has developed basic maneuvering skills and how it would best be taught.

There are several reasons why more parent supervised practice driving may be better than less, if undertaken under the best conditions: (1) novice teens would gain experience in a range of driving conditions; (2) some aspects of driving, such as visual scanning, managing distraction, and self restraint might become somewhat automatized; and (3) parents would have ample opportunity to impress their children with the importance of safe driving behavior. However, as noted, it is unknown how much supervised driving practice is needed for higher order skill to develop, or whether practice is enough. Moreover, while the adoption of GDL may have increased the amount of parent supervised practice driving in many states, specific efforts to increase it have not proved successful (see table 2).

Goodwin et $a^{26}$ evaluated the effects of an information booklet developed by the Network of Employers for Traffic Safety (NETS). The booklet, which provided general tips about teaching teenagers to drive and planning practice driving sessions, was delivered at the time teens obtained a learner's permit. While the participants reported about 40-50 hours of supervised practice driving, no effects of the intervention on the amount of practice driving were found. Similarly, a study was conducted in Tennessee with parents of teens who had just obtained learners' permits. One group received a motivational letter and the second group received the letter and NETS booklet. The third group received the same materials as the second group plus four informational cards sent out at twomonth intervals. There was no effect of intervention on supervised practice driving or parent supervision of novice teen driving upon licensure ${ }^{41}$ These studies relied on the simple distribution of print materials about supervised practice driving, and it is possible that more comprehensive approaches might yield greater effects. However, at present there is no evidence that parents will increase the amount or change the way they supervise their children's practice driving when encouraged to do so, or that it is possible to do so. 


\section{Increasing parental management of novice teen independent driving}

The Checkpoints Program is the first of its type with demonstrated efficacy for increasing parent imposed restrictions on teen driving privileges during the first year of driving (see Simons-Morton and $\operatorname{Hartos}^{24}$ ). Studies that have as a goal increasing parental management of independent novice teen driving are presented in table 2 and described in the following pages.

The Checkpoints Program is designed to increase parent limits on novice teen independent driving, especially under high risk conditions, consistent with GDL provisions. However, it extends the GDL concept through the use of persuasive communications in the form of a video, newsletters, and a parent-teen driving agreement. These materials are designed to alter attitudes towards the risks of teen driving, perceptions about parental norms regarding restrictions, and expectations about adopting strict driving limits. The goal of the program is for families to adopt the Checkpoints parent-teen driving agreement and establish and maintain driving restrictions during the first year of licensure. Studies have examined the acceptability of aspects of the program components and tested the efficacy and effectiveness in several randomized controlled trials.

\section{Acceptability}

A pilot study has demonstrated that exposure to the newsletters alter parental attitudes towards the risks of teen independent driving and the benefits of restricting it. ${ }^{42}$ In addition, when given the driving agreement, most families reported using and liking it, and adopting the Checkpoints Program recommendations for strict initial limits on teen independent driving at night, with teen passengers, and on high speed roads. ${ }^{42}$ Later studies also report favorable parent experience with the program. ${ }^{43}$

\section{Efficacy}

In the first of two randomized trials, teens and parents were recruited at one Maryland State Department of Motor Vehicles (DMV) licensing office at the time the teen successfully tested for a provisional license. Weeks were randomized to intervention or comparison so that all the parent-teen dyads recruited during the intervention week viewed the Checkpoints video, received the parent-teen driving agreement, and were verbally encouraged by a research assistant to negotiate the agreement. Study participants were interviewed at the time of recruitment and one, four, and nine months after licensure. The results indicated parents and teens in the Checkpoints Program were more likely to report using a driving agreement and to communicate about driving rules. Intervention teens and parents reported significantly more restrictions on teen passengers and high speed roads at licensure plus four months and overall limits through nine months post-licensure. Despite a decline in limits over time, treatment significant group effects persisted through nine months post-licensure. ${ }^{44} 45$ In a second efficacy trial, families were recruited at the time the teen obtained a learner's permit and randomized to intervention or comparison conditions. Families then received materials in the mail periodically over the learner's permit period and for the first six months of licensure. Baseline driving expectations and driving limits at licensure predicted later limits. Families who received the Checkpoints materials reported significantly greater restrictions on teen driving at licensure through 12 months post licensure, but limits declined over time. ${ }^{43}$

\section{Effectiveness}

The Checkpoints Program was evaluated in a large trial in Connecticut that examined the effects on parental restrictions, risky driving, traffic violations, and crashes during the first year of driving. Nearly 4000 families were involved in the study, recruited at the time the teen obtained a learner's permit and randomized to intervention or comparison group. The video was sent to participating families and newsletters were mailed every few months throughout the permit period and first six months of licensure. Just before obtaining a license, the Checkpoints parent-teen driving agreement was mailed to intervention families. Treatment group differences were found at licensure on driving limits, expected limits, risk perceptions, and outcome expectations; the last two were found to mediate the intervention effect on driving limits. ${ }^{46}$ Treatment group effects were also found for driving limits through six months post-licensure and on risky driving and traffic violations assessed at 12 months. There was no main effect of intervention on crashes, but there were indirect effects of intervention through increased driving limits on risky driving, violations, and crashes. ${ }^{47}$

These studies have demonstrated that families can be recruited and retained in the Checkpoints Program, despite the commitment required and the competing demands on the time and attention of busy families. Over $85 \%$ of eligible families were recruited and $80 \%$ were retained up to 18 months. Another trial is now being fielded that will test the effectiveness of Checkpoints when integrated into routine DMV office practice.

\section{Translational research}

Several other trials are underway to determine if the Checkpoints Program can be implemented productively in other practice settings. Michigan has a unique two-stage driver education program, and most teens take the second segment shortly before licensure, making it an optimal time to focus on driving privileges. The efficacy of implementing Checkpoints within this second segment is currently being evaluated. Parents are invited to an additional driver education classroom session, where parents and teens view the video, get a brief motivational lecture, and negotiate the initial aspects of the parent-teen driving agreement.

An interactive electronic version of Checkpoints is in development and will be evaluated in a state that provides a parent supervised, home driver education program alternative to the traditional professional driver training.

Insurance companies provide other possible practice settings in which to facilitate increases in parent management. Apart from licensing bureaus and parents, insurance companies and their agents may be the only other groups in direct and reasonably frequent contact with young drivers once they obtain their licenses. While many companies currently offer information about the dangers of teen driving, with some even providing some type of parent-teen driving agreement, no systematic evaluations of these initiatives have been conducted.

\section{Summary of intervention effects}

The available research provides evidence for the efficacy and effectiveness of interventions to improve parental management of independent driving among novice teen drivers. While a great deal remains to be learned about parent involvement, some things seem reasonably clear based on the available research:

- The few trials that have been conducted provide no evidence that print based interventions can increase or improve parent supervised practice driving.

- Both observational and intervention studies indicate that teens whose parents limit initial independent driving privileges engage in less risky driving and are less likely to have tickets and crashes. 
- Parent limits are strictest at licensure and the extent of initial limits predicts future limits, teen risky driving, violations, and crashes. However, limits decline sharply from licensure through 12 months.

- Parent limits on teen driving can be increased through persuasive methods. The relative advantages of persuasion delivered during the learner's permit period or at intermediate license are currently being evaluated in a randomized controlled trial.

- Some important mediators of parent management, including risk perceptions and social norms, have been identified and modified in randomized controlled trials.

- Some parent limits are easier to influence than others. Parents tend to set greater limits on trip conditions, relating to permission to drive, than on risk conditions, such as the number of teen passengers, night driving, and road and weather conditions.

- Parent limits may be greater when GDL is in place in a state than when it is not.

\section{CONCLUSION}

Parents have important roles to play in the management of teen driving. Increased involvement in supervised practice driving is an implicit goal of some GDL policies, but has not been well facilitated and little is known about this process or its ultimate effects on teen driving outcomes. Some programmatic attention has been focused over the years on increasing and improving parent supervision of practice driving during the learner's permit period. However, it is not clear that increases in parent supervised practice driving can be achieved easily or if substantial increases would have safety effects during independent driving.

Independent driving among novice teenagers poses considerable safety risks, regardless of the amount of supervised practice driving during the licensure period. Much of this risk may be attributable to learning effects because risk declines rapidly during the initial months of licensure, and then more slowly for several years. This is consistent with classic learning curves seen with complex behaviors, but in the case of driving, this has more dramatic consequences than with most behaviors. If independent novice teen driving is inherently dangerous, teenagers should be protected from driving under the highest risk conditions, at least until they gain substantial independent driving experience. This is the premise of GDL. The positive safety effects of GDL, perhaps due in large part to parental enforcement, could be enhanced by increased parental management during the early months of independent driving. A growing body of research has shown that it is possible to increase parent limits on newly licensed teens, and that increased limits protect teens from negative driving outcomes.

Parental management programs are also highly portable and several trials are underway that attempt to integrate the Checkpoints Program into driver education and DMV offices. Elements of the successful parent management programs, including persuasive communications and model parent-teen driving agreements, could be incorporated into driver education during the learner stage, and at intermediate or full licensure at local DMV offices. The effectiveness of parental management programs might be enhanced by timing their delivery and arranging the content to coincide with parental interest, for example, by targeting parental expectations during teens' practice driving, providing parentteen driving agreements at the time of licensure, and then targeting maintenance of parental restrictions after licensure. Also, more needs to be learned about how to improve both parent management of novice teen drivers and the impact of parent intervention. Research is needed testing how the dose,

\section{About the senior author}

Bruce Simons-Morton is Chief of the Prevention Research Branch in the Division of Epidemiology, Statistics, and Prevention Research at the National Institute of Child Health and Human Development, National Institutes of Health, where he directs a program of research on child and adolescent health behavior. Dr Simons-Morton's research on teen driving has focused on the nature of teen driving risks, the benefits and status of parental limits on teen driving privileges, and evaluation of the effects of the Checkpoints Program on parental management of newly licensed teens. Dr Simons-Morton received his MS from San Diego State University, an MPH from the Johns Hopkins University School of Public Health, and a doctorate in Education from the University of Northern Colorado.

timing, content, and delivery of persuasive messages might be altered to obtain greater effects on the targeted mediators and outcomes and provide the most efficient intervention in a range of contexts such as driver education classes and DMV offices.

\section{ACKNOWLEDGEMENTS}

This paper was first presented as part of the first Expert Panel meeting of the Youthful Driver Research Initiative, a collaborative research program between the Center for Injury Research and Prevention (http://www.chop.edu/injury) at the Children's Hospital of Philadelphia (CHOP) (http://www.chop.edu) and State Farm Insurance Companies ${ }^{\circledR}$ (State Farm) (http://www.statefarm.com). The views presented in this paper are those of the author(s) and are not necessarily the views of CHOP or State Farm.

\section{Authors' affiliations}

B Simons-Morton, M C Ouimet, National Institute of Child Health and Human Development, Bethesda, MD, USA

\section{REFERENCES}

1 Anderson RN, Smith BL. Deaths: Leading Causes for 2001. National Vital Statistics Reports 2003:52:1-85.

2 Anderson RN, Minino AM, Fingerhut LA, et al. Deaths: Injuries, 2001. National Vital Statistics Reports 2004;52:1-86.

3 McCartt AT, Shabanova VI, Leaf WA. Driving experience, crashes and traffic citations of teenage beginning drivers. Accid Anal Prev 2003;35:311-20.

4 Page $Y$, Ouimet MC, Cuny S. An evaluation of the effectiveness of the supervised driver-training system in France. Proc Assoc Adv Automot Med Conf 2004;48:131-48.

5 Sagberg F, Gregersen NP. Effect of lower age limit for practising. In Underwood G (ed). Traffic and transport psychology: theory and application. Proceedings of the ICTTP 2004. Amsterdam, the Netherlands: Elsevier Science Ltd, 2005:171-8.

6 Williams AF, Ferguson SA. Rational for graduated licensing and the risks it should address. Inj Prev 2002;8(Suppl 2):9-14.

7 Foss R, Goodwin A. Enhancing the effectiveness of graduated driver licensing legislation. J Safety Res 2003;34:79-84.

8 Langley JD, Wagenaar AC, Begg DJ. An evaluation of the New Zealand graduated driver licensing system. Accid Anal Prev 1996;28:139-46.

9 Shope JT, Molnar U. Graduated driver licensing in the United States: evaluation results from the early programs. J Safety Res 2003;34:63-9.

10 Shope JT, Molnar U, Elliot MB, et al. Graduated driver licensing in Michigan: early impact on motor vehicle crashes among 16-year-old drivers. JAMA 2001;286:1593-8.

11 Mayhew DR, Simpson HM, Ferguson SA, et al. Graduated licensing in Ontario: A survey of parents. J Traffic Med 1999:27:71-80.

12 Waller PF, Olk ML, Shope JT. Parental views of and experience with Michigan's Graduate Licensing Program. J Safety Res 2000;31:9-15.

13 Williams AF, Ferguson SA, Leaf WA, et al. Views of parents of teenagers about graduated licensing systems. J Safety Res 1998;29:1-7.

14 Simons-Morton BG, Hartos JL. How well do parents manage young driver crash risks? J Safety Res 2003;34:91-7.

15 Brown ID, Groeger JA, Biehl B. Is driver training contributing enough towards road safety? In: Rothengatter JA, de Bruin RA (eds). Road users and traffic safety. Assen, the Netherlands: Van Gorcum, 1987:135-56.

16 Mayhew DR, Simpson HM, Williams AF, et al. Effectiveness and role of driver education and training in a graduated licensing system. J Public Health Policy $1998 ; 19: 51-67$ 
17 Potvin L, Champagne F, Laberge-Nadeau C. Mandatory driver training and road safety: the Quebec experience. Am J Public Health 1988;78:1206-9.

18 Lund AK, Williams AF, Zador P. High school driver education: Further evaluation of the DeKalb county study. Accid Anal Prev 1986;18:349-57.

19 Robertson LS. Crash involvement of teenaged drivers when driver education is eliminated from school. Am J Public Health 1980;70:599-603.

20 Levy DT. The effect of driving age, driver education, and curfew laws on traffic fatalities of 15-17 years olds. Risk Anal 1988;8:327-34.

21 Vernick JS, Li G, Ogaitis S, et al. Effects of high school driver education on motor vehicle crashes, violations, and licensure. Am J Prev Med 2006; 16(1S): 40-46.

22 Berg HY. Reducing accidents and injuries among young drivers: what kind of prevention should we be focusing on? Inj Prev 2006;12(Suppl 1):i15-i18.

23 Gregersen NP. What should be taught? Basic vehicle control skills or higher order skills? In: Simpson HS (ed). New to the road: reducing the risks for young motorists. Los Angeles, CA, Youth Enhancement Service, Brain Information Service, 1996:103-14.

24 Simons-Morton BG, Hartos J. Improving the effectiveness of counter measures to motor vehicle crashes among young drivers. J Health Educ 2003;34:S57-S61.

25 Insurance Institute for Highway Safety. Licensing sytems for young drivers. Arlington, VA: Insurance Institute of Highway Safety, 2005.

26 Goodwin AH, Waller MW, Foss RD, et al. Parental supervision of teen drivers in a graduated licensing system. Chapel Hill, NC: University of North Carolina Highway Safety Research Center, 2006.

$27 \mathrm{Hall} \mathrm{J}$, West R. Role of formal instruction and informal practice in learning to drive. Ergonomics 1996;39:693-706.

28 Page $Y$, Ouimet MC, Cuny S. Estimation du risque relatif $d$ 'implication accidentelle des jeunes conducteurs ayant suivi l'Apprentissage Anticipé de la Conduite [Relative risk of accident of young drivers who followed the Apprentissage Anticipé de la Conduite drivers' training]. Final Report. Nanterre, France: Centre Européen d'Études de Sécurité et d'Analyse des Risques et Fondation MAIF, 2004.

29 Gregersen NP, Berg H-Y, Engstrom I, et al. Sixteen years age limit for learner drivers in Sweden-an evaluation of safety effects. Accid Anal Prev 2000;32:25-35

30 Groeger JA. Understanding driving: applying cognitive psychology to a complex everyday task. Hove, UK: Psychology Press, 2000.

31 Gregersen NP, Nyberg A, Berg H-Y. Accident involvement among learner drivers - an analysis of the consequences of supervised practice. Accid Anal Prev 2003;35:725-30.

32 Mayhew DR, Simpson HM, Pak A. Changes in collision rates among novice drivers during the first months of driving. Accid Anal Prev 2003;35:683-91.
33 Hartos JL, Eitel P, Haynie DL, et al. Can I take the car? Relations among parenting practices and adolescent problem-driving practices. J Adolesc Res 2000;15:352-67.

34 Hartos J, Eitel P, Simons-Morton BG. Parenting practices and adolescent risky driving: A three-month prospective study. Health Educ Behav 2002;29:194-206.

35 Hartos JL, Eitel P, Simons-Morton BG. Do parent-imposed delayed licensure and restricted driving reduce risky driving behaviors among newly licensed teens? Prev Sci 2001;2:113-22.

36 Hartos JL, Beck KH, Simons-Morton BG. Parents' intended limits on adolescents approaching unsupervised driving. J Adolesc Res 2004; 19:591-606.

37 Hartos JL, Shattuck T, Simons-Morton BG, et al. An in-depth look at parentimposed driving rules: Their strengths and weaknesses. J Safety Res 2004;35:547-55.

38 Beck KH, Hartos JL, Simons-Morton BG. Parent-teen disagreement of parentimposed restrictions on teen driving after one month of licensure: is discordance related to risky teen driving? Prev Sci 2005;26:1-9.

39 Goodwin AH, Foss RD. Graduated driver licensing restrictions: awareness, compliance, and enforcement in North Carolina. J Safety Res 2004;35:367-74

40 Hartos JL, Simons-Morton BG, Beck KH, et al. Parent-imposed limits on highrisk adolescent driving: are they stricter with graduated driver licensing? Accid Anal Prev 2005;37:557-62.

41 Chaudhary N, Ferguson SA, Herbel S. Tennessee's Novice Driver Safety Project: a program to increase parental involvement. Traffic Inj Prev 2004;5:356-61.

42 Hartos JL, Nissen WJ, Simons-Morton BG. Acceptability of the checkpoints parent-teen driving agreement-pilot test. Am J Prev Med 2001 ;21:138-41.

43 Simons-Morton BG, Hartos JL, Leaf WA, et al. Persistence of effects of the checkpoints program on parental restrictions of teen driving privileges. Am J Public Health 2005:95:447-52.

44 Simons-Morton BG, Hartos JL, Beck KH. Persistence of effects of a brief intervention on parental restrictions of teen driving privileges. Inj Prev 2003;9:142-6

45 Simons-Morton BG, Hartos JL, Beck KH. Increased parent limits on teen driving: Positive effects from a brief intervention administered at the motor vehicle administration. Prev Sci 2004;5:101-11.

46 Simons-Morton BG, Hartos JL, Leaf WA, et al. Cognitive mediation of the effect of persuasive materials on parent-imposed driving limits of novice young drivers. J Adolesc Res (in press).

47 Simons-Morton BG, Hartos JL, Leaf WA, et al. Do recommended driving limits affect tickets and crashes during the first year of teen independent driving? Traffic Inj Prev (in press). 